\title{
Chronic fatigue syndrome and quality of life
}

This article was published in the following Dove Press journal:

Patient Related Outcome Measures

\section{Deb Roberts}

Liverpool CFS Therapy Service, Royal Liverpool and Broadgreen University Hospitals, Liverpool, UK
Correspondence: Deb Roberts Ward 10, Alexandra Wing, Broadgreen Hospital, Thomas Drive, Liverpool, Merseyside LI4 3LB, UK

Tel +44 I5I 2826185

Fax +44 I5I $2826 \mid 88$

Email deborah.roberts@rlbuht.nhs.uk

\begin{abstract}
Chronic fatigue syndrome (CFS), also known as myalgic encephalomyelitis (ME), is a challenging long-term condition (LTC) with complex and fluctuating symptoms. It is heterogeneous in presentation without diagnostic indicators; therefore, in health care encounters, insight must be gained from the patient's perspective. One indicator of impact can be gained by measuring quality of life (QoL). By applying a patient-reported outcome measure (PROM), professionals can gather insights with direct relevance to the patient questioned. Such a tool can act therapeutically tool to promote holistic and individualized professional interventions and interval measurement can inform commissioning of specialist services. Standard practice appears not fully to capture the experience of CFS, while a search of the literature turned up QoL patient-reported outcome tools, but failed to reveal a CFS/ME-specific measure. The author explores a valid and reliable PROM that can monitor change and evaluate the UK National Institute of Clinical Excellence rehabilitation program, as delivered by specialist National Health Service units. An alternative, the World Health Organization's quality-of life instrument (WHOQoL)-Bref26, is reviewed for relevance to the condition, measuring treatment outcomes and the wider debate of measuring QoL in LTCs.
\end{abstract}

Keywords: long-term conditions, patient perspective, assessment, quality of life, measurement

\section{Introduction}

\section{Background}

Approximately 15.4 million of the population in England report a long-term condition (LTC). ${ }^{1,2}$ Monitoring patients' level of disability by assessing overall effect on quality of life (QoL) is regarded as essential by the author. ${ }^{3}$ A 2010 white paper ${ }^{4}$ emphasized the ability of patient-reported outcome measures (PROMs) to enhance LTC management, not to be confused with satisfaction surveys. ${ }^{5}$ Nevertheless, the Medical Research Council $^{6}$ and Reuben and Tinetti ${ }^{7}$ intimate that general tools may inadequately reflect experiences or the outcome of intervention in many LTCs. The author observes that despite best professional efforts, gaining a measurable understanding of the effect of chronic fatigue syndrome (CFS) and demonstrating the effectiveness of interventions can be considered problematic. ${ }^{8,9}$ PROMs are developing into a versatile intervention that provides a rich data set and acts as a quality-improvement tool. ${ }^{9}$ However, measures need to be sensitive enough to capture complex variables and the impact of comorbidities ${ }^{10}$ and to inform clinical commissioning. ${ }^{11}$

The UK National Institute of Health and Care Excellence (NICE) CFS program delivered by specialist services promotes accurate diagnosis and practical recom- 
mendations that emphasize working in partnership, taking account of needs and preferences. An overview of strategies is offered in this article in relation to what the author is seeking to measure. Managing both the physical and emotional components of the condition with an individualized approach includes cognitive behavioral and (for some) graded exercise approaches. NHS tertiary services, along with many other specialties, do not form part of The UK National Clinical Audit and Patient Outcomes Programme. ${ }^{12,13}$ However, intensive users of the expensive health care services, the author is aware of the urgency to positively influence the LTC-reporting agenda and CFS specifically. ${ }^{14,15}$ This review seeks to explore a valid and reliable care measure that captures QoL, monitors change, and evaluates practice.

\section{The condition}

CFS, also known as myalgic encephalomyelitis (ME), is an LTC with significant and unpredictable symptoms and uncertain duration. ${ }^{6}$ Often referred to as ME/CFS in leading literature, new descriptors are under discussion. ${ }^{16}$ However, the NICE guidelines descriptor of CFS/ME will be the term applied in this article. As CFS/ME is heterogeneous in nature and without medical or diagnostic markers, those with the illness are frequently disbelieved, despite the dramatic changes to functional abilities and emotional well-being. ${ }^{17}$ GPs are likely to have up to 40 patients experiencing symptoms, and upward of $50 \%$ will need input from specialist services. ${ }^{18}$ The author agrees with Reynolds et al, ${ }^{19}$ who emphasized the extensive burden of CFS/ME symptoms that require robust initiatives and without which prognosis is poor. The UK NICE guideline estimates a minimum prevalence in primary care of $0.2 \%,{ }^{6}$ although a unified case definition or etiology is yet to achieve consensus..$^{20}$ Despite fierce debate, there is a suggestion that physiological, neurological, and/ or autoimmune dysfunction combine to produce devastating physical, emotional, social, and economic consequences. ${ }^{21}$

Prior to the development of symptoms, patients most frequently report severe illness, surgery, accident, and/or physical and psychological or emotional trauma. ${ }^{22}$ Evidence exists that under the influence of such triggers, the condition begins with circadian rhythm dysregulation. ${ }^{23} \mathrm{~A}$ debilitating fatigue that is unlike everyday tiredness and not resolved by sleep or rest is reported, along with difficulties in memory and concentration. ${ }^{24}$ The developing sleep disorder results in daytime sleep, and the enforced rest rapidly develops into severe muscle deconditioning. ${ }^{25}$ Often described as the "payback phenomenon", patients recount an increase in symptoms of myalgia, dizziness, and tachycardia. ${ }^{26}$ Although not fully understood, symptoms including nausea, muscle tension, and disruption to bowel and bladder function also occur. It appears that the autonomic nervous system and fight-or-flight response are more greatly activated as patients attempt to maintain their previous functional lifestyle and responsibilities levels. ${ }^{26}$ Sufferers experience a downward spiral of physical symptoms that can result in reactive anxiety and depression. ${ }^{27,28}$ Fenouillet et $\mathrm{al}^{29}$ confirms that pathogenesis appeare to be multifactorial. ${ }^{30}$

\section{Current practice}

The minimum data set (MDS) of PROMs agreed upon by the British Association of CFS/ME Professionals (BACME) ${ }^{7}$ utilizes well-recognized and validated measures (Table 1). Fatigue, sleep, and self-efficacy are reviewed in a well-replicated format, although the questions are general in nature. ${ }^{31-33}$ Pain is represented by a visual analog scale. ${ }^{34}$ Many very specific but perhaps not entirely relevant physical activity descriptors are captured with the Short Form (SF)-36 - physical function scale, ${ }^{35}$ and mood through the Hospital Anxiety and Depression Scale (HADS) ${ }^{36}$ In common with other CFS specialists, the author suggests that HADS can confuse mood change with the results of fatigue. A narrow exploration of QoL is included through the EuroQol (EQ)-5D, ${ }^{37}$ the Clinical Global Improvement scale rating overall change at discharge when the MDS is repeated..$^{38}$ The emphasis has been to assess

Table I Questionnaires

\begin{tabular}{|c|c|}
\hline & Description \\
\hline $\begin{array}{l}\text { Chalder Fatigue } \\
\text { Questionnaire }^{31}\end{array}$ & $\begin{array}{l}\text { Ten questions designed to describe difficulties } \\
\text { with fatigue and associated symptoms, with four } \\
\text { scored categories ranging from } 0 \text { (less than) to } \\
3 \text { (much more than) }\end{array}$ \\
\hline Epworth & Eight activity inquiries and likelihood of sleeping: \\
\hline Sleepiness Scale $\mathrm{e}^{32}$ & 0 (never) to 3 (high chance of dozing) \\
\hline $\begin{array}{l}\text { Self-Efficacy } \\
\text { Scale for Chronic } \\
\text { IIIness }^{33}\end{array}$ & $\begin{array}{l}\text { Six inquiries beginning "How confident are you } \\
\text {.." managing fatigue, physical, emotional/other } \\
\text { symptoms, tasks, and other on a 10-point scale: } \\
\text { I (not confident) to } 10 \text { (completely confident) }\end{array}$ \\
\hline $\begin{array}{l}\text { Visual Analog } \\
\text { Scale - pain }\end{array}$ & Measured $0-100 \%$ \\
\hline Short Form $36^{35}$ & $\begin{array}{l}\text { Ten questions about physical activity, with three } \\
\text { responses: I (limited a lot), } 2 \text { (a little), or } 3 \text { (not } \\
\text { at all) }\end{array}$ \\
\hline $\begin{array}{l}\text { Hospital Anxiety } \\
\text { and Depression } \\
\text { Scale }^{36}\end{array}$ & $\begin{array}{l}\text { Mood measure with seven questions for anxiety } \\
\text { and seven for depression; four score responses: } \\
0 \text { (no impact) to } 3 \text { (frequently affected) }\end{array}$ \\
\hline $\begin{array}{l}\text { European Quality } \\
\text { of Life Measure }\end{array}$ & $\begin{array}{l}\text { Five questions on mobility, self-care, activity, } \\
\text { pain, and mood in three categories: I (no } \\
\text { problems) to } 3 \text { (extremely disabling) difficulties }\end{array}$ \\
\hline $\begin{array}{l}\text { Clinical Global } \\
\text { Impression }^{38}\end{array}$ & $\begin{array}{l}\text { Seven questions, with responses ranging from I } \\
\text { (very much better) to } 7 \text { (very much worse) }\end{array}$ \\
\hline
\end{tabular}


changes in physical function and ensure mood is monitored within specialist care. ${ }^{12}$

However, the author finds the prescribed questionnaires time-consuming, with limited suitability as therapeutic tools. The measures do not explore social, leisure, or work domains to any degree, neglecting intimacy and a more detailed QoL assessment. The complexity of scoring and the national database design for CFS/ME PROMs results requires expert interpretation, which is no longer feasible to provide. As qualitative analysis reveals ambiguities and fails to capture patient representation, the ability to report successful outcomes to influence the planning and commissioning of local health care services may prove inadequate. ${ }^{39}$

\section{What are we trying to measure?}

Endorsed by the NHS Outcomes Framework, ${ }^{40}$ measuring what is important to the patient is regarded as the most therapeutic approach. Along with practitioners in LTC management, CFS/ME specialists are seeking insight into symptoms and impact of the condition on function, health behavior, and capacity to self-manage. ${ }^{41}$ Devlin and Appleby ${ }^{42}$ observed that self-assessment of health and health-related QoL informed patient decision-making regarding treatment and lifestyle choices. There is increasing recognition of the need to understand personal experience of illness and patient needs better to foster shared decision-making. ${ }^{42}$ As Wearden et $\mathrm{al}^{43}$ confirmed, CFS/ME continues to be a diagnosis of exclusion through the fulfillment of symptom criteria without a clinical diagnostic test. ${ }^{12}$ Though not discussed in this paper, Fukuda et $\mathrm{al}^{24}$ offered frequently applied criteria for diagnosis and to support research into the condition. $\mathrm{NICE}^{12}$ go further, emphasizing the prerequisite of symptoms of fatigue and postexertion malaise, without which the condition cannot be confirmed. Difficulties remain, with many models offering elucidation and treatment options, but what is regarded as recovery remains contested. ${ }^{44}$

The most researched and endorsed treatment approaches currently include lifestyle and physical regimes and psychological therapies. ${ }^{45-48}$ Acknowledging and understanding the source of symptoms such as fatigue, pain, anxiety, and low mood is promoted by NICE. ${ }^{8}$ Sleep hygiene, the concept of pacing activity with rest,${ }^{41}$ physical reconditioning, and a realistic return to commitments is addressed through grading and for some exercise. ${ }^{8,49}$ However, tackling the resulting loss and managing stress are also addressed. Examining one's own and others' expectations and workplace pressures are complemented with relaxation techniques and lifestyle goal setting. ${ }^{49}$ Health professionals practicing in CFS/ME rehabilitation have observed that positive change also requires a degree of acceptance and rediscovering meaning in life, despite the lack of full understanding of the mechanics of the condition. ${ }^{50,51}$ What practitioners are aiming for initially is stability. ${ }^{12}$ Pemberton and $\operatorname{Cox}^{26}$ point out that patients' traumatic experiences and personality style are also elements to address in therapeutic encounters. Nelson et $\mathrm{al}^{41}$ highlight the positive impacts of building confidence and resilience with relapse-prevention skills that prevent setbacks and protect health and well-being. ${ }^{51}$ In order to fully capture specialist treatment, Jason et $\mathrm{al}^{20}$ stress the importance of a comprehensive self-reporting tool to support assessment of biopsychosocial symptomatology, impact, and specialist interventions.

Devlin and Appleby ${ }^{42}$ confirm measuring and benchmarking the performance of health care providers is necessary for patient safety, but Nelson et al warn an emphasis on measuring patient experiences must not misdirect the focus of therapy or become practitioner priorities. ${ }^{41}$ The application of PROMs in everyday practice has the potential to narrow the gap between practitioners' and patients' views of clinical reality and help tailor treatment plans to meet preferences applicable to CFS/ME and LTCs in general. Nelson et $\mathrm{al}^{41}$ further observed that without the application of PROMs, health professionals' understanding of the effect of complex disease and interventions is insufficient.

\section{Literature review}

Material was accessed through Ebsco's electronic library search engine, employing Boolean operators to refine logical relationships among terms. CINAHL Complete, Information Science and Technology, Medline, PsycArticles, and PsycInfo databases were retrieved. Scopus (through SciVerse), the Cochrane Library, PubMed, and Web of Science were also reviewed, with closely overlapping results. The content of prominent journals similarly informed appraisal by highlighting both historic and recent development drivers and clinical and political interest in the subject. A starting year of 1990 was chosen to coincide with the growth in PROM development. Those outside Europe, Australia, and North America were excluded, due to lack of familiarity or availability. The literature review sought to gather the most widely replicated and validated measures in studies most closely resembling the project setting. Results were very widely ranging, but selected as relating to adults with a diagnosis of CFS/ME as per the Fukuda criteria, which despite its potential shortcomings is 
the most frequently applied diagnostic guide. ${ }^{24}$ Findings were scrutinized for their ability to provide meaningful direction. ${ }^{52}$

The search revealed an absence of uniform insights and a wide variety of interventions. ${ }^{53-56}$ Also sought was evidence of research into the application of PROMs for CFS/ME. CFS-specific measures proved to be few and not consistently evaluated..$^{57}$ Devlin and Appleby ${ }^{42}$ observed that the sheer number of clinical measures made a comparison of health impacts problematic, and the author found that the PROMs utilized in prominent $\mathrm{UK}$-based CFS/ME research generally measured the efficacy of cognitive, behavioral, and graded exercise therapies. The most consistently applied questionnaires were the Chalder Fatigue Questionnaire, ${ }^{31}$ full SF36, ${ }^{35}$ HADS,${ }^{36}$ and the Clinical Global Impression scale. ${ }^{38}$ With such reputable and consistently reproducible findings, these results have been influential in formulating NICE guidelines and continue to inform NHS tertiary care..$^{12,25,43,58}$ Nevertheless, focus has centered on symptom description and reduction, rather than capturing QoL.

\section{What are the alternatives?}

Inquiries into the most fit-for-purpose PROMs for CFS/ ME were not forthcoming. ${ }^{57} \mathrm{CFS} / \mathrm{ME}$-specific measures showed limited evidence of practical application, consistency, or score interpretation. Despite Peters et a ${ }^{59}$ stressing the multifarious nature of LTCs, narrow symptom domains in single trials were found and samples were modest. ${ }^{24}$ The literature review revealed extremely limited evidence of QoL-research design or reliable practice monitoring in CFS/ ME. ${ }^{12,30}$ The full SF36 was the most prevalent measure, with well-corroborated design that addresses a range of categories, although regarded more of a health status questionnaire. ${ }^{35} \mathrm{Of}$ the 36 questions, 14 relate to physical capability, ten entries record limitation to physical function, and four changes to physical role. The severity and disruption caused by pain is reviewed by two entries, and five points focus on health perception. Only two questions capture the extent and frequency of health problems disrupting social activity, but eight entries aim to assess mood, with three relating to emotional impact on activity. A general health description and comparison to others uses five questions.

Of the publications focusing on QoL, there was a combination of measuring physical function, psychological distress, and well-being. They concluded with powerful results that CFS has a pervasive negative impact. ${ }^{60}$ Hvidberg et $\mathrm{al}^{61}$ echoed this finding through application of the EQ5D. Nonetheless, the author regards this measure as too generally defined. Taylor ${ }^{62}$ and Taylor et al's ${ }^{63}$ work on QoL and well-being themes in CFS/ME were collated through the Frisch Quality of Life Inventory for LTCs. ${ }^{64}$ Valuable insights were gained through accounts of the measure, but the tool was not readily available. Query and Taylor ${ }^{65}$ demonstrated positive change through goal attainment, a good tool with which to report the effects of therapy, but the scale was restricted to a linear one-item domain. Haywood et al's systematic review ${ }^{57}$ confirmed that well-validated generic PROMs are applied in $\mathrm{CFS} / \mathrm{ME}$ research and practice, but exhibit wide variation and lack sensitivity. They also revealed minimal assessment of measures' applicability to the condition. Nevertheless, the review reinforced the belief that capturing changes in QoL as a measure of progress is essential.

It fell to van Heck and Vries's ${ }^{66}$ comparative study of QoL in healthy volunteers and those with CFS/ME to introduce the World Health Organization's QoL instrument (WHOQoL) and specifically the brief version (Bref26). ${ }^{67,68}$ Despite being a further generic tool and one that left Schoofs et $\mathrm{al}^{69}$ with unanswered questions, there was applicability to the condition. Devised around the same time as the full SF36 and now revised to 26 items, the WHOQoL-Bref26 contains all the categories recommended by the BACME, with better clarity between emotional distress and self-esteem. ${ }^{35}$ General health self-assessment and sexual function are new concepts, while requesting perceptions of satisfaction with work capability, safety, and leisure pursuits gives greater insight. Energy is considered separately to sleep quality, and fatigue is not rated against prescriptive activities.

Skevington and McCrate's review of 27 disease groups and healthy controls with over 4,600 participants applied the WHOQoL-Bref26 to CFS/ME. ${ }^{68}$ A valid comparison to the SF36 was demonstrated, distinct QoL profiles gained, and greater sensitivity to change recorded. The Bref26 employs closed questions that gather quantitative responses, grouped into four domains. There are seven physical, six psychological, three social, and eight environmental descriptors to complete. QoL and health status are measured independently of the domains, with each question scoring 1-5. Skevington and $\mathrm{McCrate}^{68}$ report completion times ranged from 2-240 minutes, with an average 20 minutes per patient. Only $3 \%$ required assistance in their study. The findings demonstrated acceptability and feasibility of use.

\section{Discussion Demographics}

The demographic questions found in the first section of the WHOQoL-Bref26 are relevant to the UK setting. In the clinical setting, CFS/ME prevalence is high in age-groups 
spanning between 20 and 50 years, with the majority having high academic background and professional occupation, as confirmed by Collin et al. ${ }^{70}$ As emphasized by Arroll and Senior, ${ }^{71}$ capturing such measurements is essential to tailoring clinical care. Identifying the right "at-risk" groups also promotes targeted primary-care promotion and protection advice and equips all parties to recognize signs and symptoms. ${ }^{61}$

\section{Symptoms}

As a generic questionnaire, the WHOQoL-Bref26 does not record a category of symptoms, as demonstrated in the criteria required for diagnosis. ${ }^{12}$ Rather, this information is obtained initially from GP opinions at referral (Table 2). However, it is not until one-to-one assessment several months into the therapy program that a comprehensive personal account is taken. The author agrees with Arroll and Senior ${ }^{71}$ that such information can act as a concise and accurate checklist and be a welcome addition to PROMs. Without this perspective change, function and satisfaction with life and health may be considered in isolation. Jason et $\mathrm{al}^{20}$ emphasize the need for a more unified case definition.

\section{Table 2 UK NICE definition of CFS}

\section{Guidelines for evaluation and diagnosis}

Fatigue with the following symptoms:

- new or had a specific onset (ie, not lifelong)

- persistent and/or recurrent

- unexplained by other conditions

- has resulted in substantial reduction in activity level characterized by postexertion malaise and/or fatigue (typically delayed, eg, by at least 24 hours, with slow recovery over several days)

and one or more of the following symptoms:

- difficulty with sleeping, such as insomnia, hypersomnia, unrefreshing sleep, disturbed sleep-wake cycle

- muscle and/or joint pain that is multisite and without evidence of inflammation

- headaches

- painful lymph nodes without pathological enlargement

- sore throat

- cognitive dysfunction, such as difficulty thinking, inability to concentrate, impairment of short-term memory, and difficulties with word finding, planning/organizing thoughts, and information processing

- physical or mental exertion or flu-like symptoms

- dizziness and/or nausea

- palpitations in the absence of identified cardiac pathology

The symptoms of CFS/ME fluctuate in severity, and may change in nature over time.

Notes: Reproduced with permission from (๑) NICE (2007) CG53 Chronic fatigue syndrome/myalgic encephalomyelitis (or encephalopathy): diagnosis and management. ${ }^{8}$ Available from www.nice.org.uk/guidance/cg53. All rights reserved. Subject to Notice of rights NICE guidance is prepared for the National Health Service in England. All NICE guidance is subject to regular review and may be updated or withdrawn. NICE accepts no responsibility for the use of its content in this product/publication.

Abbreviations: CFS, chronic fatigue syndrome; ME, myalgic encephalomyelitis; NICE, National Institute of Health and Care Excellence.

\section{Severity}

NICE guidelines attribute a scale of severity to the condition that is applied at diagnosis: from mild to very severe. For most patients, their diagnosis is confirmed from the review of a completed referral that shows a clear correlation with the criteria. ${ }^{12}$ As this information is provided from the GP's perspective, there can be inconsistencies. It is the one-to-one assessment that provides a detailed account, directed by the skilled specialist, but recounted by the patient. Accompanied by completion of a second set of PROMs, a comparison of symptoms and severity cannot be fully accurate. Dancey and Friend ${ }^{27}$ stressed the importance of capturing the effects of illness intrusiveness, and Arroll and Senior ${ }^{71}$ suggested offering more symptomatology descriptors and a rating from low to high severity, as outlined in the UK guideline. ${ }^{6}$ The PROM under consideration goes some way toward rating the severity of symptoms through functional and lifestyle limitation on a 5-point Likert scale. ${ }^{72}$

\section{Phenotypes}

As highlighted by Jonsjö et al, ${ }^{73}$ there remains ambiguity regarding a diagnosis of $\mathrm{CFS} / \mathrm{ME}$ as one disease. The presentation of heterogeneous symptoms indicates important differences, as does the wide variation in daily functioning. Subgroups of symptoms seem plausible, and identifying phenotypes or profiles may explain differences, while anticipating the impact of symptoms on function. ${ }^{69,70,72}$ White et $\mathrm{al}^{25}$ believed CFS/ME was an illness in which physiological and psychological factors interacted to cause and maintain dysfunction. The WHOQoL-Bref26 allows a distinguishing of presentations as defined by the patient, with a question asking whether the respondent considers themselves ill. The results can then be related to the primary reporting problem, demonstrating differing combinations of experienced symptoms and disabilities. Arroll and Senior ${ }^{70}$ also suggested mood, fatigue, postexertion malaise, and neurological and gastrointestinal to be relevant classifications of further distinction.

\section{Complex comorbidities}

Hvidberg et $\mathrm{al}^{61}$ observed that in addition to $\mathrm{CFS} / \mathrm{ME}$, those with the condition frequently report an average of up to three other chronic illnesses. The author has found that due to complex comorbidities, some presentations have reduced capacity for improvement, as Skevington and McCrate ${ }^{68}$ also demonstrated. In contrast, those outlining a singular diagnosis of CFS/ME demonstrate higher scores in QoL, health status, function, and circumstances, according to the author's observations. The opportunity to document the illness experience in free text on the WHOQoL-Bref26 is thus a valuable indicator. 


\section{Functional classification}

The WHOQoL-Bref26 allocates seven questions to the first domain, the physical component of the questionnaire. They include pain, mobility, sleep, and the ability to carry out activities of daily living. Energy levels are also noted, a classic symptom of the condition. However, the need for medical treatment to function and capacity to work are broad inquiries and more multifaceted than the WHOQoL-Bref26 assumes. It is important to consider the complexities of CFS/ $\mathrm{ME}$, which is frequently regarded as more globally disabling than many other conditions. ${ }^{6,42}$

Domain two contains psychological descriptors such as enjoyment and meaning in life. How accepting the participant is of their body image and satisfaction with self are elements of QoL frequently very compromised in CFS/ME, due to physical limitations and mood. ${ }^{8}$ Only one question aims to capture anxiety and depression, but the assessment process undertaken at the service measures risk in depth. The author questions the categorizing of concentration as psychological, which the CFS specialist professionals would reclassify, regarding cognitive difficulties as physical and related to sleep disorder. ${ }^{3}$ The author would also advocate for a question related to memory, as this cognitive function is frequently compromised. ${ }^{22}$ Nijs et al ${ }^{46}$ concurred that the experience of such symptoms is not psychological in effect.

Social inquiry is relatively limited in domain three of the WHOQoL-Bref26, with only three questions allocated. This contrasts sharply to responses patients give as they describe the isolation, lack of understanding, and loss of relationships that come with social limitation. ${ }^{25}$ The final domain seeks to gain insight into environment impact. Here, opinion is sought on the health and safety of the physical environment, as well as asking about conditions of living space. Financial provision and the availability of information are grouped with access to health services and transport availability. Leisure also falls into this category, although the author would highlight the large overlap with social satisfaction. ${ }^{69}$

\section{QoL}

QoL can be defined as an individuals' perceptions of their life situation, related to culture, goals, and the value system they subscribe to ${ }^{66}$ When measuring aspects such as QoL, Nacul et $a \mathrm{l}^{50}$ suggested that generic measures (unlike disease-specific tools) can make more accurate comparisons to healthy individuals, as demonstrated by Skevington and McCrate ${ }^{68}$ in studying a range of other diseases. The first question measures QoL, which Dancey and Friend ${ }^{27}$ stressed is extensively affected in CFS/ME, permeating all valued aspects of lifestyle, activity, and interests. The application of the SF36 and EQ5D can provide only limited insight of the associated loss. ${ }^{49}$ Low QoL is distinct in CFS/ME, according to Collin et $\mathrm{al},{ }^{70}$ although this finding was disputed by Jonsjö et al. ${ }^{73}$ Nonetheless, Skevington and McCrate ${ }^{68}$ compared 27 health conditions, reporting distinct QoL profiles among them.

\section{Health status}

The term "health status" refers to medical conditions and experiences of both disability and health care service encounters. ${ }^{66}$ As disability in CFS/ME is reportedly multidimensional, Lowry et a ${ }^{60}$ stressed the importance of measures of functional status and well-being, to characterize health status; this is the second question in the WHOQoL-Bref and also a stand-alone score. Skevington and $\mathrm{McCrate}^{68}$ emphasized that personal beliefs and health expectations were integral to assessing QoL, due to their reciprocal influence. The questionnaire goes on to broadly assess how physical and psychological health, independence, and social contact form complex relationships. ${ }^{66,67}$

\section{Pain}

Arroll and Senior ${ }^{71}$ highlighted predominant-symptom subgroups of pain or fibromyalgia-like symptoms, a condition with many overlapping symptoms and treatments. ${ }^{74}$ Many of the patients treated at the author's center have a dual diagnosis, which does not cause therapeutic conflict. The questionnaire reviews the impact of pain on QoL, but asks whether the sensations stop what the informant needs to do, rather than what they would want to do, which may produce different results. Nijhof et al ${ }^{75}$ observed that pain is disabling in CFS/ME, affecting both physical and social functioning. The author can confirm from clinical experience that such symptoms can be as severe as physical and cognitive fatigue, influencing all aspects of QoL and rates of improvement.

\section{Work and interests}

The impact of CFS/ME results in disruptions to productivity and meaningful occupation, which is often not the case with other conditions. ${ }^{25}$ Many are forced to give up work and interests, due to both physical and cognitive demands that cannot be sustained. As the workplace for many provides friendship, belonging, and identity, and significant loss and reduced self-worth is experienced. ${ }^{26}$ Greater understanding of these issues helps to dispel the misconception that CFS/ ME patients are malingerers. ${ }^{15}$ Nonetheless, modest attention is given in the WHOQoL-Bref26, with question 18 capturing satisfaction with capacity to work. Inquires related 
to the physical environment, money, and leisure could also be seen to make tentative links to difficulties that have wide-reaching consequences. ${ }^{6}$ Taylor et $\mathrm{al}^{63}$ highlighted an interrelationship with fear of exacerbation of symptoms, having too little energy to engage in physical exertion, creating a negatively influencing cycle on social interaction and work capability. Nevertheless, quantifying what reduces isolation and increases understanding and support through the WHOQoL-Bref26 alone may be challenging. Specialist-clinic group programs, education of supporters, and (of equal influence) improvement in physiology and symptoms, gained through management strategies, are all influencing factors.

\section{Relationships}

A further explanation of reduction in satisfaction with significant relationships was offered by Nacul et al, ${ }^{50}$ who highlighted the emotional impact of the condition on carers and supporters. Relationships suffer, as fatigue prevents social contact and intimacy. ${ }^{68}$ The WHOQoL-Bref26 offers only three inquiries related to relationships and support. It does, nevertheless, offer clarity of just how limited interaction becomes by asking about sexual intimacy. The author reports that the inclusion of this question can cause a negative reaction for some respondents, who leave it blank or suggest this is not for discussion. This theme is echoed in sessions when an apology is often issued before approaching the issue with the therapist. This is a significant indicator of disability influencing QoL frequently neglected.

\section{Self-efficacy}

The NICE-led rehabilitation approach delivered in the service in question aims to build self-efficacy through education and support. ${ }^{8}$ Defined as confidence in executing actions and managing a wide array of situations, improvement in such abilities frequently correlates with treatment progression. This aspect of health status is not addressed directly in the WHOQoL-Bref26, with the closest inquiry coming from a question that asks how much the patient needs medical treatment to function. This is suggestive of change resulting from reduced physical symptoms, but could also be interpreted as measuring successful self-management and independence. Question 13 asks whether the respondent has the information they need, and question 24 about access to health services. Both could be interpreted as related to self-efficacy, but are placed in the environmental domain, and are thus regarded as obtuse. Kennedy et $\mathrm{al}^{76}$ found that measuring progress in patients' self-confidence is not straightforward.

\section{Mood}

Nacul et $\mathrm{a}^{50}$ were keen to point out that lack of energy may well not be the most disabling feature, as in addition to physical disability, CFS/ME has a significant reactive impact on mental health. Those describing being ill with a mood disorder are likely to score the lowest in all domains and exhibit the most modest change. ${ }^{67} \mathrm{Nacul}$ et $\mathrm{al}^{50}$ agreed that the impact of symptoms reduced psychological well-being dramatically revealed in a higher rate of depression than comparative groups. Daniels et $\mathrm{al}^{77}$ discovered a 33\%-42\% prevalence of anxiety and depression with atypical presentation. On first glance at the WHOQoL-Bref26, it appears that mood impact is gathered through a singular inquiry question 26. Responses to the question of negative feelings, anxiety, low mood, and feeling "blue" are never, seldom, quite often, very often, and always. However, the comprehensive psychological domain asks about enjoyment, meaning, body image, and satisfaction with self, a rounded picture from which the therapist can tailor individualized treatment and without which difficulties will remain. ${ }^{76}$ As Dancey and Friend ${ }^{27}$ observed, the perception of not being taken seriously accounts in part for higher illness-worry scores, low meaning in life, and depression in CFS/ME, a causal relationship associated with feeling delegitimized. ${ }^{76}$ The author identifies with the urgency to consider in depth the level and impact of emotional stress. ${ }^{28}$

\section{Accuracy}

The PROMs applied at the author's center seek firstly to gain information on referral. One-to-one assessment to evaluate progress from group therapy provides a second opportunity and informs the individualized contact to come, on average 8 months after initial acceptance. The final questionnaire reviews individualized therapy at discharge, which varies but can be up to a year later. Nevertheless, the earliest point of intervention has been observed to be when the condition is at its most fluctuating and the respondent most unrealistic about their limitations. Currently, the service utilizes only two of the originally recommended BACME MDS: the SF36 - physical function (eleven items) ${ }^{34}$ and Chalder Fatigue Questionnaire. ${ }^{30}$ Both place a large emphasis on the physical domain. The former is frequently inaccurate, as scores often diminish with acceptance and insight into the reality of the condition. ${ }^{48}$ The latter fails to interpret the physical lack of energy as a valid cause for reduced cognitive functioning. Neither emphasizes the impact and measurement of QoL. The existing measures risk greater inaccuracy than the WHOQoL-Bref26. 


\section{Conclusion}

The author suggests that the WHOQoL-Bref26 has the capacity to record the demographics of CFS/ME populations ${ }^{60,69}$ and to highlight how disabling CFS/ME can be from the patient's perspective by showing the impact of the condition on important activities. ${ }^{58}$ Patients' views and feelings should not be regarded as inadequate or an inappropriate basis for making important decisions. ${ }^{77}$ Capturing personal health perspectives relays what helps patients feel better and more able to achieve everyday functions. The WHOQoL-Bref26 asks about the effect of the condition on QoL, rather than capabilities, and is applicable at any and multiple stages of therapy. The questionnaire has a less challenging format than other measures, as patients have influenced the design, rather than researchers. Respondents are able to report from their own context, capture beliefs, and communicate personal values and goals. ${ }^{66,67}$ The heterogeneity and impact of complex comorbidities are also accounted for. ${ }^{72}$ Wiering et $\mathrm{al}^{78}$ describe how patient-designed measures prove more acceptable and meet the challenges the CFS/ME patient group faced. These have a broader remit than the Chalder Fatigue Scale $^{30}$ and can consider a wider range of impact.

LTCs have complex components, such as have been seen in the outline of CFS/ME, with comorbidities and the influence of depression and anxiety. ${ }^{2,76}$ The concise nature of the WHOQoL-Bref26 makes it suitable for application and use during professional-patient interaction and as a therapeutic tool. ${ }^{40}$ Fluctuations due to circumstances and stressors influencing scores are difficult to account for. ${ }^{19,28}$ However, the WHO emphasizes that measurement must account for changes in the severity of the illness and also provide an estimate of well-being. ${ }^{67}$ Therefore, the WHOQoL-Bref26 has the potential to evidence the quality of care outcomes. ${ }^{8}$ PROMs data are subjective, and as Devlin and Appleby ${ }^{42}$ described, purposefully so. Nevertheless, a reliable and wellvalidated questionnaire is essential to produce quantitative data. ${ }^{58}$ The WHOQoL-Bref26 has the potential to fill the gap identified in $\mathrm{CFS} / \mathrm{ME}$ practice and capture change delivered through therapeutic interventions, ${ }^{6}$ being less resourceintensive and able to increase accuracy in reporting. Devlin and Appleby ${ }^{42}$ outlined the importance of measuring and benchmarking the performance of health care providers.

The WHOQoL-Bref26 offers but a small snapshot of illness presentation and progression, with severity and longevity being recorded elsewhere. Nacul et $\mathrm{al}^{50}$ argued that a lack of specificity of symptoms makes disease characterization and disability assessment challenging. Facility to include this information would expand understanding and planning of tailored interventions. Nelson et $\mathrm{al}^{41}$ warned against clinicians believing they knew enough about their patients' problems and only regarding measurement as additional to their workload. The author thus endorses further work with primary-care physicians. Stenhoff et $\mathrm{al}^{17}$ confirmed that the condition receives little attention in the medical curriculum. Patients continue to report a lengthy period to diagnosis, frequently experiencing blame, and being held accountable for their poor health. ${ }^{78}$ Devlin and Appleby ${ }^{42}$ stressed the relevance of disease-specific measures, but cautioned against relying on overall scores that lose the descriptive richness of accounts and unique experiences. Bayliss et $\mathrm{al}^{79}$ warned that a skeptical view remains wherein, without a lack of identifiable pathology in CFS/ME there is no real illness, and at best symptoms are purely somatic. The author intends to explore further alternatives that could prove able to measure with even greater sensitivity CFS/ME's characteristically long and unpredictable course..$^{24,65,67}$

\section{Acknowledgments}

The author wishes to thank her clinical colleagues for their involvement and enthusiasm, both in personal encouragement and a commitment to innovation and excellence in practice.

\section{Disclosure}

The author reports no conflicts of interest in this work.

\section{References}

1. Massey L, Williams S. Implementing change: the perspective of NHS change agents. Leadersh Org Dev J. 2006;27(8):667-681.

2. NHS England. Five year forward view. 2014. Available from: https:// www.england.nhs.uk/wp-content/uploads/2014/10/5yfv-web.pdf. Accessed March 31, 2018.

3. Komaroff AL, Buchwald D. Symptoms and signs of chronic fatigue syndrome. Rev Infect Dis. 1991;13 Suppl 1:S8-S11.

4. Department of Health. Equity and excellence: liberating the NHS. 2010. Available from: https://www.gov.uk/government/uploads/system/ uploads/attachment_data/file/213823/dh_117794.pdf. Accessed March 31, 2018.

5. Williams A. How to ... write and analyse a questionnaire. J Orthod. 2003;30(3):245-252.

6. Medical Research Council. Patient-reported outcome measures (PROMS): identifying UK research priorities. 2009. Available from: https://www.mrc.ac.uk/documents/pdf/patient-reported-outcomemeasures-proms-identifying-uk-research-priorities 1. Accessed March 31, 2018.

7. Reuben DB, Tinetti ME. Goal-oriented patient care: an alternative health outcomes paradigm. $N$ Engl J Med. 2012;366(9):777-779.

8. National Institute for Health and Care Excellence. Chronic Fatigue Syndrome/Myalgic Encephalomyelitis (or Encephalopathy): Diagnosis and Management. London: NICE; 2007.

9. Crawley E, Collin SM, White PD, Rimes K, Sterne JA, May MT. Treatment outcome in adults with chronic fatigue syndrome: a prospective study in England based on the CFS/ME National Outcomes Database. QJM. 2013;106(6):555-565. 
10. Friedberg F. Does graded activity increase activity? A case study of chronic fatigue syndrome. J Behav Ther Exp Psychiatry. 2002;33(3-4):203-215.

11. Ham C, Berwick D, Dixon J. Improving quality in the English NHS. 2016. Available from: https://www.kingsfund.org.uk/sites/default/ files/field/field_publication_file/Improving-quality-Kings-FundFebruary-2016.pdf. Accessed March 31, 2018.

12. Fereday S. A Guide to Quality Improvement Methods. London: Healthcare Quality Improvement Partnership; 2015.

13. Department of Health. Guidance on the routine collection of patient reported outcome measures. 2009. Available from: http://www.healthcare-today.co.uk/doclibrary/documents/pdf/152_guidance_on_routine_collection.pdf. Accessed March 31, 2018.

14. Boyce MB, Browne JP. Does providing feedback on patient-reported outcomes to healthcare professionals result in better outcomes for patients? A systematic review. Qual Life Res. 2013;22(9):2265-2278.

15. NHS Scotland. Scottish good practice statement on Me-CFS.2010. Available from: http://www.scot.nhs.uk//wp-content/uploads/2015/06/ GoodPracticeStatement.pdf. Accessed May 01, 2018.

16. Institute of Medicine. Beyond Myalgic Encephalomyelitis/Chronic Fatigue Syndrome: Redefining an Illness. Washington: National Academies Press; 2015.

17. Stenhoff AL, Sadreddini S, Peters S, Wearden A. Understanding medical students' views of chronic fatigue syndrome: a qualitative study. $J$ Health Psychol. 2015;20(2):198-209.

18. Marques MM, de Gucht V, Gouveia MJ, Leal I, Maes S. Differential effects of behavioral interventions with a graded physical activity component in patients suffering from chronic fatigue (syndrome): an updated systematic review and meta-analysis. Clin Psychol Rev. 2015;40:123-137.

19. Reynolds KJ, Vernon SD, Bouchery E, Reeves WC. The economic impact of chronic fatigue syndrome. Cost EffResour Alloc. 2004;2(1):4

20. Jason LA, Sunnquist M, Brown A, et al. Examining case definition criteria for chronic fatigue syndrome and myalgic encephalomyelitis. Fatigue. 2014;2(1):40-56.

21. Christley Y, Duffy T, Everall IP, Martin CF. The neuropsychiatric and neuropsychological features of chronic fatigue syndrome: revisiting the enigma. Curr Psychiatry Rep. 2013;15(4):353.

22. Ene $\mathrm{S}$. Faces of fatigue: ethical considerations on the treatment of chronic fatigue syndrome. AJOB Neurosci. 2013;4(3):22-26.

23. Gotts ZM, Ellis JG, Deary V, Barclay N, Newton JL. The association between daytime napping and cognitive functioning in chronic fatigue syndrome. PloS One. 2015;10(1):e0117136.

24. Fukuda K, Strauss SE, Hickie I, Sharpe MC, Dobbins JG, Komaroff A. The chronic fatigue syndrome: a comprehensive approach to its definition and study. Ann Intern Med. 1994;121(12):953-959.

25. White PD, Goldsmith KA, Johnson AL, et al. Comparison of adaptive pacing therapy, cognitive behaviour therapy, graded exercise therapy, and specialist medical care for chronic fatigue syndrome (PACE): a randomised trial. Lancet. 2011;377(9768):823-836.

26. Pemberton S, Cox DL. Experiences of daily activity in chronic fatigue syndrome/myalgic encephalomyelitis (CFS/ME) and their implications for rehabilitation programmes. Disabil Rehabil. 2014;36(21): 1790-1797.

27. Dancey CP, Friend J. Symptoms, impairment and illness intrusiveness: their relationship with depression in women with CFS/ME. Psychol Health. 2008;23(8):983-999.

28. Deary V, Chalder T, Sharpe M. The cognitive behavioural model of medically unexplained symptoms: a theoretical and empirical review. Clin Psychol Rev. 2007;27(7):781-797.

29. Fenouillet E, Vigouroux A, Steinberg JG, et al. Association of biomarkers with health-related quality of life and history of stressors in myalgic encephalomyelitis/chronic fatigue syndrome patients. J Transl Med. 2016;14:251.

30. British Association of Chronic Fatigue Syndrome (BACME)/ME BACME: therapy and symptom management in CFS/ME. Available from: https://www.bacme.info/sites/bacme.info/files/file-attachments/ BACME $\% 20$ Therapy $\% 20 \% 26 \% 20$ Symptom $\% 20$ Management $\% 20$ Guide.pdf. Accessed May 01, 2018.
31. Chalder T, Berelowitz G, Pawlikowska T, et al. Development of a fatigue scale. J Psychosom Res. 1993;37(2):147-153.

32. Johns MW. A new method for measuring daytime sleepiness: the Epworth sleepiness scale. Sleep. 1991;14(6):540-545.

33. Lorig KR, Sobel DS, Ritter PL, Laurent D, Hobbs M. Effect of a selfmanagement program on patients with chronic disease. Eff Clin Pract. 2001;4(6):256-262.

34. Crichton N. Visual analogue scale. J Clin Nurs. 2001;10(5):697-706.

35. Ware JE Jr, Sherbourne CD. The MOS 36-item short-form health survey - I: conceptual framework and item selection. Med Care. 1992;30(6):473-483.

36. Zigmond AS, Snaith RP. The hospital anxiety and depression scale. Acta Psychiatr Scand. 1983;67(6):361-370.

37. Janssen MF, Pickard AS, Golicki D, et al. Measurement properties of the EQ-5D-5L compared to the EQ-5D-3L across eight patient groups: a multi-country study. Qual Life Res. 2013;22(7):1717-1727.

38. Guy W. ECDEUAssessment Manual for Psychopharmacology. Bethesda (MD): National Institute of Mental Health; 1976.

39. NHS Clinical Commissioners. Delivering a healthier future. 2016. Available from: https://445oon4dhpii7gjvs2jih81q-wpengine.netdna-ssl. com/wp-content/uploads/2016/01/NHSCC-Delivering-a-healthierfuture-FINAL.pdf. Accessed April 10, 2017.

40. Department of Health. The NHS Outcomes Framework 2015/16. London: National Health Service; 2014

41. Nelson EC, Eftimovska E, Lind C, Hager A, Wasson JH, Lindblad S. Patient reported outcome measures in practice. BMJ. 2015;350:g7818.

42. Devlin NJ, Appleby J. Getting the Most Out of PROMs: Putting Health Outcomes at the Heart of NHS Decision-Making. London: King's Fund; 2010.

43. Wearden AJ, Dowrick C, Chew-Graham C, et al. Nurse led, home based self help treatment for patients in primary care with chronic fatigue syndrome: randomised controlled trial. BMJ. 2010;340:c1777.

44. Adamowicz JL, Caikauskaite I, Friedberg F. Defining recovery in chronic fatigue syndrome: a critical review. Qual Life Res. 2014;23(9): 2407-2416.

45. Thomas M, Smith A. An evaluation of counselling and rehabilitation courses for chronic fatigue syndrome. Couns Psychother Res. 2007;7(3):164-171.

46. Nijs J, van Eupen I, Vandecauter J, et al. Can pacing self-management alter physical behavior and symptom severity in chronic fatigue syndrome? A case series. J Rehabil Res Dev. 2009;46(7):985-986.

47. Rimes KA, Wingrove J. Mindfulness-based cognitive therapy for people with chronic fatigue syndrome still experiencing excessive fatigue after cognitive behaviour therapy: a pilot randomized study. Clin Psychol Psychother. 2013;20(2):107-117.

48. Larun L, Brurberg KG, Odgaard-Jensen J, Price JR. Exercise therapy for chronic fatigue syndrome. Cochrane Database Syst Rev. 2015;(2): CD003200.

49. Brooks SK, Rimes KA, Chalder T. The role of acceptance in chronic fatigue syndrome. J Psychosom Res. 2011;71(6):411-415.

50. Nacul LC, Lacerda EM, Campion P, et al. The functional status and well-being of people with myalgic encephalomyelitis/chronic fatigue syndrome and their carers. BMC Public Health. 2011;11:402.

51. Robinson M, Hanna E, Raine G, Robertson C. Extending the comfort zone: building resilience in older people with long-term conditions. $J$ Appl Gerontol. 2017;1:0733464817724042.

52. Greenhalgh J, Brown T. Quality assessment: where do I begin? In: Boland A, Cherry MG, Dickson R, editors. Doing a Systematic Review: A Student's Guide. London: Sage; 2014:61-83.

53. Brouwers FM, van der Werf S, Bleijenberg G, van der Zee L, van der Meer JW. The effect of a polynutrient supplement on fatigue and physical activity of patients with chronic fatigue syndrome: a double-blind randomized controlled trial. QJM. 2002;95(10):677-683.

54. McDermott C, Richards SC, Thomas PW, Montgomery J, Lewith G. A placebo-controlled, double-blind, randomized controlled trial of a natural killer cell stimulant (BioBran MGN-3) in chronic fatigue syndrome. QJM. 2006;99(7):461-468. 
55. Costigan A, Elliott C, McDonald C, Newton JL. Orthostatic symptoms predict functional capacity in chronic fatigue syndrome: implications for management. QJM. 2010;103(8):589-595.

56. Young JL. Use of lisdexamfetamine dimesylate in treatment of executive functioning deficits and chronic fatigue syndrome: a double blind, placebo-controlled study. Psychiatry Research. 2013;207(1-2):127-133.

57. Haywood KL, Staniszewska S, Chapman S. Quality and acceptability of patient-reported outcome measures used in chronic fatigue syndrome/ myalgic encephalomyelitis (CFS/ME): a systematic review. Qual Life Res. 2012;21(1):35-52.

58. Powell P, Bentall RP, Nye FJ, Edwards RH. Randomised controlled trial of patient education to encourage graded exercise in chronic fatigue syndrome. BMJ. 2001;322(7283):387-390.

59. Peters M, Crocker H, Dummett S, et al. Pilot study of patient reported outcome measures (PROMs) in primary care: report to the Department of Health. 2013. Available from: https://www.qoru.ac.uk/wp-content/uploads/2013/11/ PROMs-Pilot-Report-June-2013.pdf. Accessed March 31, 2018.

60. Lowry TJ, Pakenham KI. Health-related quality of life in chronic fatigue syndrome: predictors of physical functioning and psychological distress. Psychol Health Med. 2008;13(2):222-238.

61. Hvidberg MF, Brinth LS, Olesen AV, Peterson KD, Ehlers L. The health-related quality of life for patients with myalgic encephalomyelitis/chronic fatigue syndrome (ME/CFS). PloS One. 2015;10(7): e0132421.

62. Taylor RR. Quality of life and symptom severity for individuals with chronic fatigue syndrome: findings from a randomized clinical trial. Am J Occup Ther. 2004;58(1):35-43.

63. Taylor RR, Kulkarni S, Shiraishi Y. Conservation of resources and quality of life in individuals with chronic fatigue syndrome. J Chronic Fatigue Syndr. 2006;13(4):3-15.

64. Frisch MB. Use of the QoLI or quality of life inventory in quality of life therapy and assessment. In: Maruish ME, editor. The Use of Psychological Testing for Treatment Planning and Outcome Assessment. 3rd ed. Mahwah (NJ): Lawrence Erlbaum; 2004:749-798.

65. Query M, Taylor RR. Linkages between goal attainment and quality of life for individuals with chronic fatigue syndrome. Occup Ther Health Care. 2006;19(4):3-22.

66. van Heck GL, Vries JD. Quality of life of patients with chronic fatigue syndrome. J Chronic Fatigue Syndr. 200;10(1):17-35.

67. World Health Organization. WHOQoL: Measuring Quality of Life. Geneva: WHO; 1997.
68. Skevington SM, McCrate FM. Expecting a good quality of life in health: assessing people with diverse diseases and conditions using the WHOQoL-Bref. Health Expect. 2012;15(1):49-62.

69. Schoofs N, Bambini D, Ronning P, Bielake E, Woehl J. Death of a lifestyle: the effects of social support and healthcare support on the quality of life of persons with fibromyalgia and/or chronic fatigue syndrome. Orthop Nurs. 2004;23(6):364-374.

70. Collin SM, Nikolaus S, Heron J, Knoop H, White PD, Crawley E. Chronic fatigue syndrome (CFS) symptom-based phenotypes in two clinical cohorts of adult patients in the UK and the Netherlands. $J$ Psychosom Res. 2016;81:14-23.

71. Arroll MA, Senior V. Symptom typology and sub-grouping in chronic fatigue syndrome. Bull IACFS ME. 2009;17(2):39-52.

72. Norman G. Likert scales, levels of measurement and the "laws" of statistics. Adv Health Sci Educ. 2010;15(5):625-632.

73. Jonsjö MA, Wicksell RK, Holmström L, Andreasson A, BileviciuteLjungar I, Olsson GL. Identifying symptom subgroups in patients with ME/CFS: relationships to functioning and quality of life. Fatigue. 2017;5(1):33-42.

74. Ablin J, Fitzcharles MA, Buskila D, Shir Y, Sommer C, Häuser W. Treatment of fibromyalgia syndrome: recommendations of recent evidence-based interdisciplinary guidelines with special emphasis on complementary and alternative therapies. Evid Based Complement Alternat Med. 2013;2013:485272.

75. Nijhof SL, Priesterbach LP, Bleijenberg G, Engelbert RH, van de Putte EM. Functional improvement is accompanied by reduced pain in adolescent chronic fatigue syndrome. Pain Med. 2013;14(9):1435-1438.

76. Kennedy A, Bower P, Reeves D, et al. Implementation of self-management support for long term conditions in routine primary care settings: cluster randomised controlled trial. BMJ. 2013;346:f2882.

77. Daniels J, Brigden A, Kacorova A. Anxiety and depression in chronic fatigue syndrome/myalgic encephalomyelitis (CFS/ME): examining the incidence of health anxiety in CFS/ME. Psychol Psychother. 2017;90(3):502-509.

78. Wiering B, Boer D, Delnoij D. Patient involvement in the development of patient-reported outcome measures: a scoping review. Health Expect. 2017;20(1):11-23.

79. Bayliss K, Goodall M, Chisholm A, et al. Overcoming the barriers to the diagnosis and management of chronic fatigue syndrome/ME in primary care: a meta synthesis of qualitative studies. BMC Fam Pract. $2014 ; 15: 44$
Patient Related Outcome Measures

\section{Publish your work in this journal}

Patient Related Outcome Measures is an international, peer-reviewed, open access journal focusing on treatment outcomes specifically relevant to patients. All aspects of patient care are addressed within the journal and practitioners from all disciplines are invited to submit their work as well as healthcare researchers and patient support groups.
Dovepress

The journal is included in PubMed. The manuscript management system is completely online and includes a very quick and fair peer-review system. Visit http://www.dovepress.com/testimonials.php to read real quotes from published authors. 